\title{
A Potential Practical Process for Remdesivir
}

\author{
Liujuan Chen, * Guowei Zhang, Jinguang Liu, Jianye Jiao, Han Lin, Miao Wu, Xin Zhang \\ Address: Asymchem Life Science (Tianjin) Co., Ltd. \\ No. 71, 7th Avenue, TEDA Tianjin, 300457, P.R. China
}

ABSTRACT: A four-step synthesis of Remdesivir (1) is presented. This work focuses on challenges encountered in reproducing literature procedures for Step 1 (Glycosylation), flow chemistry and continuous processing development of Step 2 (Cyanation) and 3 (Deperotection) and process optimization of Step 4 (Phosphoramidation). Literature reports (https://dx.doi.org/10.1021/acs.oprd.0c00310 and https://dx.doi.org/10.1021/acs.oprd.0c00172: SI part) for Step 1 were repeated, but difficulties were encountered in reproducing yield and crystallization. Eventually, Step 1 product was obtained by column chromatography with $>98 \%$ HPLC purity and $40 \%$ isolated yield. Flow chemistry development of Step 2 (IY: 84\%) and continuous processing for Step 3 (IY: 63\%) was achieved. The release of toxic $\mathrm{HCN}$ was avoided and process robustness was improved. Step 4 was simplified by utilizing primary alcohol 6 directly (without protection) to react with chiral phosphoramidate, 8. Lewis Acid catalysts were evaluated by High Throughput Screening (HTS). It was discovered that $\mathrm{MgI}_{2}$ could be formed in situ using cheaper and commercially available $\mathrm{MgCl}_{2}$ and $\mathrm{NaI}$ to afford crude Remdesivir in $50 \%$ yield. After purification, Remdesivir API (1) was obtained in $>99 \%$ purity and $40.3 \%$ isolated yield.

\section{Introduction}

Remdesivir (also known as GS5743 and Veklury ${ }^{\mathrm{TM}}$ ) attracted the interest of chemists and pharmaceutical manufacturers after Gilead reported its efficacy in the treatment of CoV-2019. ${ }^{1}$ Remdesivir had finished investigation in Phase III clinical trials as a candidate to treat CoV-2019 at $2020^{2 \sim 6}$ and also showed broad-spectrum antiviral activity against SARS-CoV-2 and MERS ${ }^{7}$.

Herein, we disclose a four-step synthetic approach to Remdesivir ${ }^{8 \sim 15}$ (Scheme 1) including the challenges encountered in repeating literature procedures for Step 1, improved flow and continuous processes for Steps 2 and 3 and a coupling procedure for 6 with 8 that avoids protection of the 2'- and 3'-OH groups and utilizes in situ generated $\mathrm{MgI}_{2}$.

Recently the yield of the key coupling (Step 1) of tribenzyl ribolactone, $\mathbf{2}$ with heterocycle $\mathbf{3}$ was reported ${ }^{14}$ to be improved to $62 \%$ after crystallization so the process seemed feasible for scaleup Meanwhile, Gilead scientists reported ${ }^{16}$ an optimization of method for the critical C-glycosylation step, in which $\mathrm{NdCl}_{3}$ and $\mathrm{n}-\mathrm{Bu} 4 \mathrm{NCl}$ were employed to facilitate the addition of lactone 2 with TMS protected amine $\mathbf{3}$; however, both strategies using silane or imine protection were repeated several times with low conversion and inability to repeat the crystallization. After additional work, step 1 was accomplished with $\mathrm{nBuLi} /$ disilane/dipropylamine and purified by flash chromatography in $40 \%$ isolated yield after adjustment of purity (measured by QNMR).

Steps 2 (cyanation) and 3 (deprotection) were both conducted by flow chemistry and continuous processing and successfully achieved $84 \%$ and $65 \%$ yield respectively. The direct coupling between compound $\mathbf{6}$ and $\mathbf{8}$ was realized by the catalysis of $\mathrm{MgI}_{2}$ with $\sim 50 \%$ assay yield. Due to the limited commercial source and high price of $\mathrm{MgI}_{2}$, it was replaced by $\mathrm{MgCl}_{2}$ and NaI. Through extensive HTS experimentation it was determined that removal of the benzyl protecting groups using catalytic hydrogenation in Step 3 was not feasible leaving high levels of partially benzylated product.

Ultimately, all four steps were all scaled up in three demo batches to check the robustness of the reaction conditions at multigram scale and Remdesivir API was obtained in high purity $(>99 \%)$ with no impurities $>0.15 \%$. Data for mass balance, impurity profiles and stress tests were collected for every step.

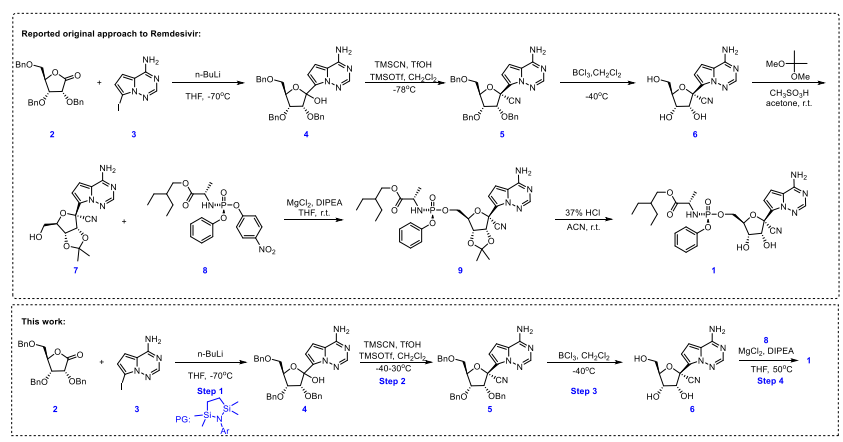

Scheme 1: Approaches to the Synthesis of Remdesivir

\section{Results and discussion}

\section{- Step 1: Reaction Screening and Summary}

Initially, two protecting group approaches were employed to improve the yield of Step 1 as shown below (Scheme 2). Di-silyl protected intermediate $\mathbf{1 0}$ was used as reported, and the imine intermediate $\mathbf{1 1}$ as isolated pure solid was used as SM for the Cglycosylation step.

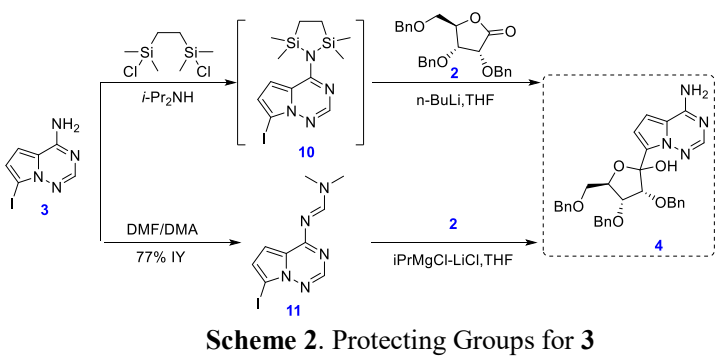


The reaction via intermediate $\mathbf{1 0}$ was repeated successfully as described in the literature ${ }^{14}$ on $10 \mathrm{~g}$ scale (Table 1, Entry 1). Pure standard sample of compound $\mathbf{4}$ was obtained by prep. HPLC with $>98 \%$ purity but was found to be only $82.3 \%$ pure by QNMR. The assay yield of the reaction solution was only $56 \%$ by HPLC. Scale-up to $100 \mathrm{~g}$ up was conducted under the same conditions in $56.7 \%$ HPLC assay yield after quench (Entry 2). After flash chromatography, 4 was obtained in $44.8 \%$ isolated yield with $96.23 \%$ purity and $80.6 \%$ QNMR assay.

Scale-up of Step 1 was attempted at $100 \mathrm{~g}$ (Entry 3) and three demo batches at $200 \mathrm{~g}$ scale (Entries 4-6) with industrial-grade 1,2-bis(trimethylsilyl) ethane. Three demo batches were combined for work-up and gave $50 \%$ assay yield. Finally, $42 \%$ isolated yield was obtained after silica-gel flash column purification. However, the commercial supply of 1,2-bis(trimethylsilyl) ethane may limit the process development for future manufacture at kilogram scale, and the quality was slightly lower than reagent grade.

Although compound 4 was reportedly ${ }^{14}$ crystallized from MTBE and n-heptane, in our hands the crude mixture, after work-up failed to crystallizate in most cases and an oily mixture was observed when cooled to $0^{\circ} \mathrm{C}$ and stirring was difficult. When 2.0 eq. of lactone $\mathbf{2}$ and 1.0 eq. of $\mathbf{3}$ was used, remaining lactone $\mathbf{2}$ and its derivatives were observed by HPLC- in-process control and could be only removed by flash chromatography due to low polarity.

Table 1: Summary of reactions via intermediate $\mathbf{1 0}$

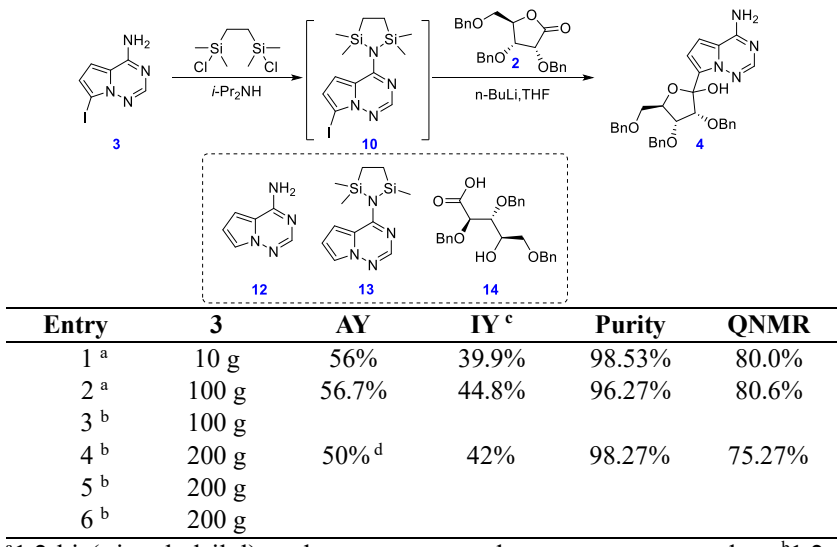

${ }^{\mathrm{a}}$ 1,2-bis(trimethylsilyl) ethane was used as reagent grade. ${ }^{\mathrm{b}} 1,2-$ bis(trimethylsilyl) ethane was purchased as industrial grade. ${ }^{\mathrm{c}}$ Isolated yield was corrected by assay. ${ }^{\mathrm{d}}$ Entries $3 \sim 6$ were combined for work-up.

Even though the de-iodo byproduct $\mathbf{1 2}$ could be washed away under acidic conditions and impurities 13 and 14 (which were observed by HPLC in-process data with $10-15 \%$ area) could be removed partially by saturated sodium bicarbonate wash, other unspecified impurities ( $\sim 50 \%$ area in total) still remained in the organic phase and needed to be removed by silica-gel flash chromatography.

Mass balance of the reaction via intermediate 10 was checked and the loss in aqueous phase was $<0.1 \%$. The major loss $(8-12 \%)$ was found from silica-gel flash chromatography purification. A stress-test was conducted to check the stability of product $\mathbf{4}$ under the work-up procedure and indicated that it was unstable under acidic conditions when quenched with $1 \mathrm{~N}$ citric acid, which was aimed to remove impurity $\mathbf{1 2}$. Hence, after quenching, the reaction mixture after phase separation needs to be done as soon as possible to avoid generation of new impurities.
The reaction via intermediate $\mathbf{1 1}^{15}$ was also screened after filtering the imine intermediate $\mathbf{1 1}$ directly from the DMF-DMA mixture with $>95 \%$ purity and $77 \%$ IY (see details in SI). The reaction at $10 \mathrm{~g}$ scale gave $40.5 \%$ assay yield that is much lower than the reaction via intermediate 10 (Table 1, Entry 1 vs Table 2, Entry 1). The in-situ prepared aromatic Grignard reagent intermediate was added to benzaldehyde and benzophenone and the reaction was complete in two hours with clean conversion, which indicated the poor reactivity of lactone 2 . To activate compound 2, Lewis Acid $\mathrm{NdCl}_{3}$ was added to the reaction (Entry 2) and $\mathrm{CeCl}_{3}$ (Entry 3) and only 39\% assay yield was obtained. In addition, a phase transfer catalyst (PTC) was added, but the purchased Lewis acids and PTC were found to be highly hygroscopic (TBAF-Entry 4), so the Lewis acid and PTC were stirred with compound 2 and distilled at atmospheric pressure for at least three times to ensure the $\mathrm{KF}$ of the mixture was $<0.1 \%$ before adding the in-situ prepared aromatic Grignard reagent. The reaction gave $40.5 \%$ assay yield. However, this condition was repeated at $50 \mathrm{~g}$ scale and only $13.8 \%$ assay yield was obtained (Entry 5).

Table 2: Summary of reactions via intermediate $\mathbf{1 1}$

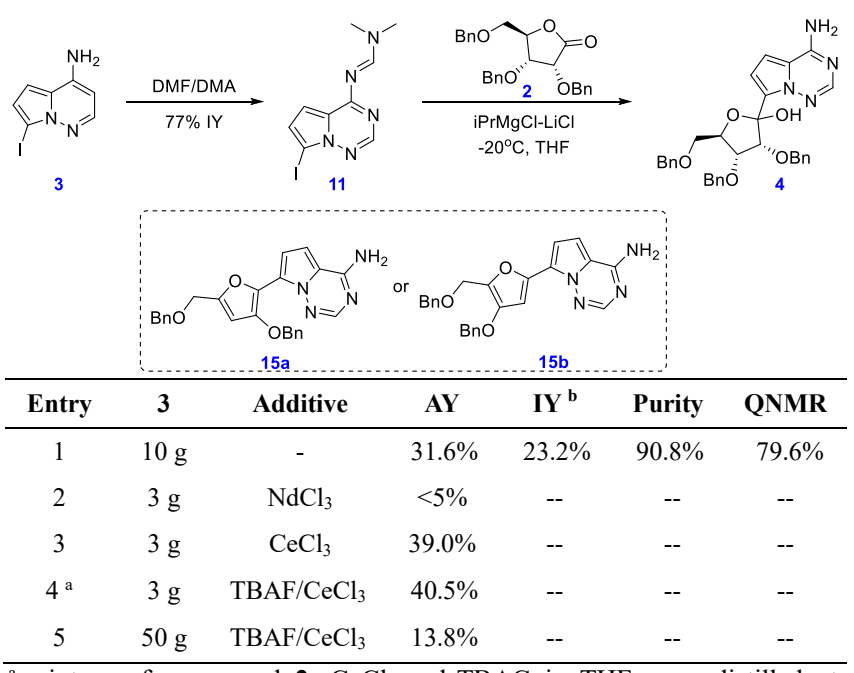

${ }^{\mathrm{a}}$ mixture of compound $\mathbf{2}, \mathrm{CeCl}_{3}$ and $\mathrm{TBAC}$ in $\mathrm{THF}$ were distilled at atmospheric pressure before adding to activated aromatic Grignard reagent; ${ }^{\mathrm{b}}$ isolated yield by flash chromatography.

The impurity profile for the reaction via intermediate $\mathbf{1 1}$ was very similar to the reaction via intermediate 10. It is noteworthy that furan impurities 15a and 15b were frequently observed. These impurities were generated after treatment of the mixture with acid for an extended period, such as quenching this reaction with acetic acid and stirred overnight at room temperature. In addition to the formation of impurities 15a and $\mathbf{1 5 b}$ another reason for low yield at $50 \mathrm{~g}$ scale was related to process robustness. Excessive amounts of solids were observed after quenching, so the mixture was filtered before separation. However, the mixture was very difficult to filter and even though a $\sim 3 \mathrm{~cm}$ thick Dicalite layer was used, the filtration required $\sim 3$ h to complete. Approximately $25 \%$ of product 4 was converted to this impurity $\mathbf{1 5 a}$ and $\mathbf{1 5 b}$ during this process and these impurities were difficult to separate from product 4 by flash chromatography. Based on these results the preferential approach was via intermediate 10. Additional studies are needed to understand our inability to repeat the literature procedures. 


\section{- Step 2: Reaction Screening and Impurity Profile}

The Flow Chemistry process for step 2 was developed by Gilead and this process was reproducible in our laboratory. ${ }^{16}$

As previously reported, the cyanation reaction was performed through combination of compound 4 (Scheme 3) in dichloromethane (DCM) with trifluoroacetic acid (TFA), trimethylsilyl trifluoromethanesulfonate (TMSOTf), and trimethylsilyl cyanide (TMSCN) in flow chemistry directly (Figure $1)$.

On the basis of the above continuous reaction conditions, solvent volume, flow rate ratio and residence time were evaluated in this study. Moreover, triethylamine quenching was added to the procedure so that smaller quantities of the hazardous reaction mixture would be rapidly quenched before the reaction stream exited the

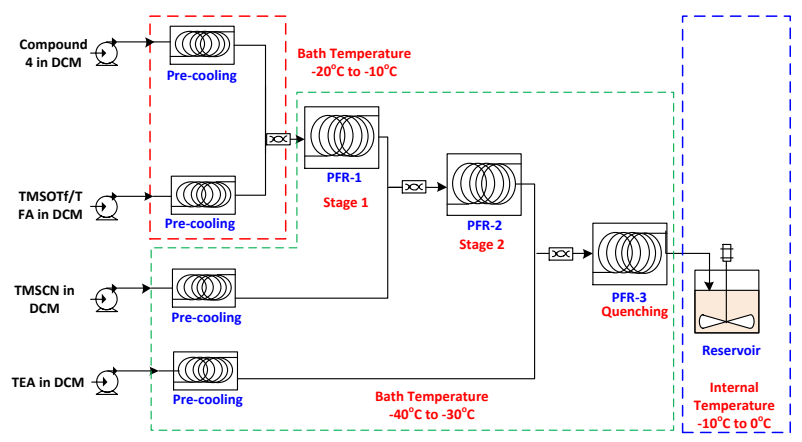

Figure 1. Schematic drawing of continuous flow chemistry setup.

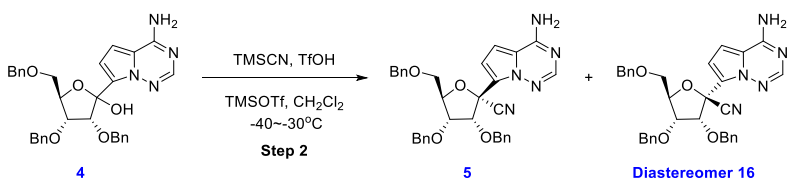

Scheme 3. Preparation of Compound 5 . reason of blockage so doubling the volume $(48 \mathrm{~V})$ of DCM was tested to confirm and the flow process conducted well without blockage (Table 3, Entry 1). After additional experimentation to evaluate the source of the plugging, it was discovered that compound 4 and TFA (melting point of $-15.4{ }^{\circ} \mathrm{C}$ ) had limited solubility in the DCM mixture at $-40{ }^{\circ} \mathrm{C}$ and likely crystallized during precooling of the feed line. To circumvent this issue the compound 4 and TFA/TMSOTf/DCM feed precooling loop temperature was increased to $-15^{\circ} \mathrm{C}$.

With the continuous flow system, an experimental run was performed to confirm the system performance. The results were obtained as expected but there was a slight increase in the residual amount of starting material $(1.16 \%)$ along with a decrease in diastereoselectivity (97:3) (Entry 2), which we speculated was due to insufficient mixing of the feed solutions with different flowrates $(2.97 / 1.21 / 1.00)$ and relatively shorter residence time. Therefore, longer residence time ( $1 \mathrm{~min}$ vs. $0.5 \mathrm{~min}$ for PFR-1 and 9 min vs. 5 min for PFR-2) was tested and the volume of DCM in each feeding solution was adjusted accordingly to make the flowrates $(1.00 / 1.20 / 1.05)$ in a similar level which was believed to afford better mixing (Entry 4). The results showed a high diastereoselectivity $(99: 1)$ with $0.06 \%$ compound 4 remaining. Evaluation of the residence times indicated that $0.5 \mathrm{~min}$ was optimal for the reaction with TMSOTf and 5 min was sufficient for the reaction with TMSCN (Entries 5 and 7).

Decreasing the equivalents of reagents was found to negatively impact the reaction performance with a decrease in both conversion and diastereoselectivity under the flow chemistry conditions (Entry 6). After acceptable continuous flow conditions were established, an in-house model system was assembled, consisting of three diaphragm metering pumps and $\varphi 3$ PFA tubing. With this system, the process was tested at $200 \mathrm{~g}$ input of compound $\mathbf{4}$ and afforded high diastereoselectivity (99:1) and a solution purity of $\mathbf{5}$ of $95.28 \%$ (Entries 9-11). Subsequent isolation of the quenched reaction stream afforded compound 5 in $84.7 \%$ yield with $98.5 \%$ purity. This larger-scale test demonstrated the viability of the continuous flow process for preparation of compound $\mathbf{5}$ with high diastereoselectivity.

Table 3. Optimization of cyanation continuous flow chemistry conditions ${ }^{\mathrm{a}}$

\begin{tabular}{|c|c|c|c|c|c|c|c|}
\hline \multirow[b]{2}{*}{ Entry } & \multirow{2}{*}{$\begin{array}{c}\text { equiv of } \\
\text { TFA/ TMSOTf/TMSCN }\end{array}$} & \multicolumn{2}{|c|}{ residence time (mins) } & \multirow[b]{2}{*}{ IPC of $4(\%)^{b}$} & \multirow[b]{2}{*}{ IPC of $5(\%)^{b}$} & \multirow[b]{2}{*}{ IPC of $16(\%)^{b}$} & \multirow[b]{2}{*}{ d.r. ${ }^{b}$} \\
\hline & & $\begin{array}{c}\text { reaction } \\
\text { loop } 1\end{array}$ & $\begin{array}{c}\text { reaction } \\
\text { loop } 2\end{array}$ & & & & \\
\hline $1^{\mathrm{c}}$ & $1 / 6 / 6$ & 0.5 & 5 & 0.65 & 85.2 & 1.84 & $98: 2$ \\
\hline $2^{d}$ & $1 / 6 / 6$ & 0.5 & 5 & 1.16 & 87.33 & 2.69 & $97: 3$ \\
\hline $3^{d}$ & $1 / 6 / 6$ & 0.25 & 2.5 & 1.57 & 86.76 & 2.54 & $97: 3$ \\
\hline 4 & $1 / 6 / 6$ & 1 & 9 & 0.06 & 83.90 & 0.33 & $99: 1$ \\
\hline 5 & $1 / 6 / 6$ & 0.5 & 5 & 0.96 & 89.40 & 0.23 & $99: 1$ \\
\hline 6 & $1 / 5 / 5$ & 0.5 & 5 & 2.5 & 89.60 & 0.39 & $99: 1$ \\
\hline 7 & $1 / 6 / 6$ & 0.2 & 2 & 14.8 & 72.00 & 5.90 & $92: 8$ \\
\hline 8 & $1 / 6 / 6$ & 0.5 & 5 & 1.3 & 88.90 & 1.70 & $98: 2$ \\
\hline 9 & $1 / 6 / 6$ & 0.5 & 5 & 0.09 & 94.35 & 0.43 & $99: 1$ \\
\hline 10 & $1 / 6 / 6$ & 0.5 & 5 & 0.18 & 93.2 & 1.07 & 99:1 \\
\hline 11 & $1 / 6 / 6$ & 0.5 & 5 & 0.75 & 95.28 & 0.48 & 99:1 \\
\hline
\end{tabular}

${ }^{a}$ Reaction conditions: Reactions were performed at $5 \mathrm{~g}$ input of compound 4 on a flow chemistry system using $\varphi 3$ PFA tubing. $24 \mathrm{~V}$ DCM in total for reaction, flow rate for SM $\sim 1.00 \mathrm{~g} / \mathrm{min}$, flow rate for TMSOTf $\sim 1.20 \mathrm{~g} / \mathrm{min}$, flow rate for TMSCN $\sim 1.05 \mathrm{~g} / \mathrm{min}$. ${ }^{\mathrm{b}}$ Purity was determined by $\mathrm{LC}$ analysis of an aliquot of the quenched reaction mixture. ${ }^{\mathrm{c}}$ Reaction conditions: $48 \mathrm{~V}$ DCM in total for reaction, flow rate for SM 2.97g/min, flow rate for TMSOTf $\sim 1.21 \mathrm{~g} / \mathrm{min}$, flow rate for TMSCN $\sim 1.00 \mathrm{~g} / \mathrm{min} .{ }^{\mathrm{d}}$ Reaction conditions: $24 \mathrm{~V}$ DCM in total for reaction, flow rate for SM $\sim 2.97 \mathrm{~g} / \mathrm{min}$, flow rate for TMSOTf $\sim 1.21 \mathrm{~g} / \mathrm{min}$, flow rate for TMSCN $\sim 1.00 \mathrm{~g} / \mathrm{min}$.

flow reactor, thereby mitigating the potential safety risks associated with the process.

During implementation of this change, the feed line experienced increased back pressure and ultimately plugged. The poor solubility under lower local bath temperature was speculated as the main

\section{- Step 3: Reaction Screening and Summary}

The current process for deprotection of benzyl groups uses $\mathrm{BCl}_{3}$ which is expensive and toxic. In order to mitigate this issue, the standard approach of catalytic hydrogenation using $\mathrm{Pd} / \mathrm{C}$ was 
evaluated using HTS. ${ }^{17}$ Unfortunately after extensive screening, we were unable to completely remove all three benzyl groups and observed two impurities from incomplete deprotection, $\mathbf{1 7}$ and $\mathbf{1 8}$ as major side products. For catalytic hydrogenation details see SI.

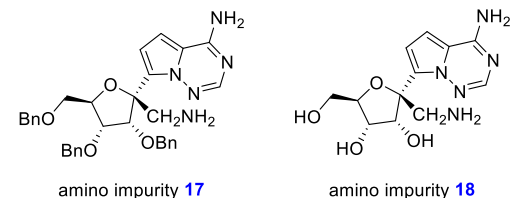

Figure 2 impurities in catalytic hydrogenation.

\section{Continuous Process for Preparation of Compound 6.}

The synthesis of compound 6 has been reported previously. ${ }^{18}$ As discussed above we were forced to use the $\mathrm{BCl}_{3}$ approach. Removal of the benzyl protecting groups of $\mathbf{5}$ was done in dichloromethane (DCM) with boron trichloride $\left(\mathrm{BCl}_{3}\right)$. The reaction required cryogenic conditions $\left(-78{ }^{\circ} \mathrm{C}\right)$ and had the potential risk to liberate significant quantities of hydrochloric acid gas which is not desirable for large-scale manufacturing. Herein we report the development of continuous flow conditions for the preparation of compound 6.

Familiarization and optimization of flow conditions were conducted in batch mode for better understanding and performance before the continuous reaction. Effect of the equivalents of $\mathrm{BCl}_{3}$ was investigated. Lowering the loading of $\mathrm{BCl}_{3}$ delivered inferior results (more Mono-Bn 2.35\% and Di-Bn 5.07\% generated, 3.0 equiv., (Entry 4) compared to that obtained with 4.0 equiv. of $\mathrm{BCl}_{3}$ (Entry 3).
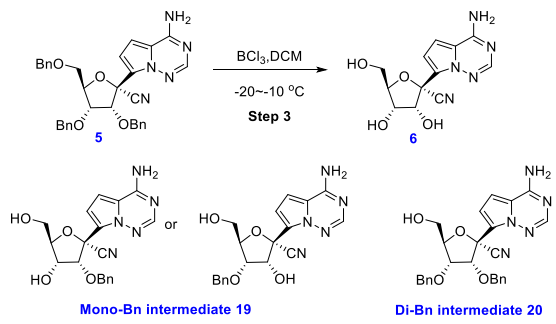

Table 4. Optimization of debenzylation reaction conditions

\begin{tabular}{ccccccc}
\hline Entry & $\mathrm{BCl}_{3}$ eq & $\mathrm{T}\left({ }^{\circ} \mathrm{C}\right)$ & $\mathbf{5}(\%)^{\mathrm{b}}$ & $\mathbf{6}(\%)^{\mathrm{b}}$ & $\begin{array}{c}\text { MonoBn } \\
(\%)^{\mathrm{b}}\end{array}$ & $\begin{array}{c}\text { Di-Bn } \\
(\%)^{\mathrm{b}}\end{array}$ \\
\hline 1 & 6 & $-50 \sim-40$ & $\mathrm{ND}$ & 71.98 & 0.75 & 0.40 \\
2 & 5.5 & $-50 \sim-40$ & ND & 71.75 & 1.40 & 1.37 \\
3 & 4.0 & $-50 \sim-40$ & ND & 65.18 & 1.85 & 0.42 \\
4 & 3.0 & $-50 \sim-40$ & 0.22 & 66.70 & 2.35 & 5.07 \\
5 & 6.0 & $-20 \sim-10$ & 0.6 & 67.1 & 0.31 & 0.8 \\
6 & 4.0 & $-20 \sim-10$ & 0.74 & 69.4 & 0.57 & ND \\
$7^{\mathrm{b}}$ & 4.0 & $-20 \sim-10$ & 0.52 & 68.6 & 0.13 & 0.17 \\
$8^{\mathrm{c}}$ & 4.0 & $-20 \sim-10$ & 0.26 & 69.9 & 0.14 & 0.34 \\
\hline
\end{tabular}

${ }^{a}$ Reaction conditions: Compound 5 in DCM (10V) was cooled to the indicated temperature, and $\mathrm{BCl}_{3}$ solution was added. ${ }^{\mathrm{b}}$ Reaction conditions: Compound 5 in DCM $(50 \mathrm{~V})$ was cooled to the indicated temperature, and $\mathrm{BCl}_{3}$ solution was added. ${ }^{\mathrm{c}}$ Reaction conditions: Compound 5 in DCM $(20 \mathrm{~V})$ was cooled to the indicated temperature, and $\mathrm{BCl}_{3}$ solution was added.

The challenges of turning the reaction into a continuous flow reaction were the requirement of low reaction temperatures $(-50 \sim-$ $40{ }^{\circ} \mathrm{C}$ ) and the generation of solids during the reaction process (Table 4, Entries 1-4). When the reaction was conducted at -20 $10{ }^{\circ} \mathrm{C}$, acceptable results were observed with reaction completion within $10 \mathrm{~min}$ (Entry 6). However, a large amount of solids was observed during the reaction process and this will lead to blockage in the continuous reaction. To further improve the practicality of the process, we sought to increase the amount of solvent and reduce the reaction concentration.

Specifically, a similar result was observed when conducting the reaction at $0.06 \mathrm{~mol} / \mathrm{L}(60 \mathrm{~V} \mathrm{DCM}$, Entry 7$)$ and $0.11 \mathrm{~mol} / \mathrm{L}(30 \mathrm{~V}$ DCM, (Entry 8), comparable to that of $0.17 \mathrm{~mol} / \mathrm{L}(20 \mathrm{~V} \mathrm{DCM}$, Entry 1).

\section{Preparation of Compound 6 via Continuous Stirred Tank Reactor.}

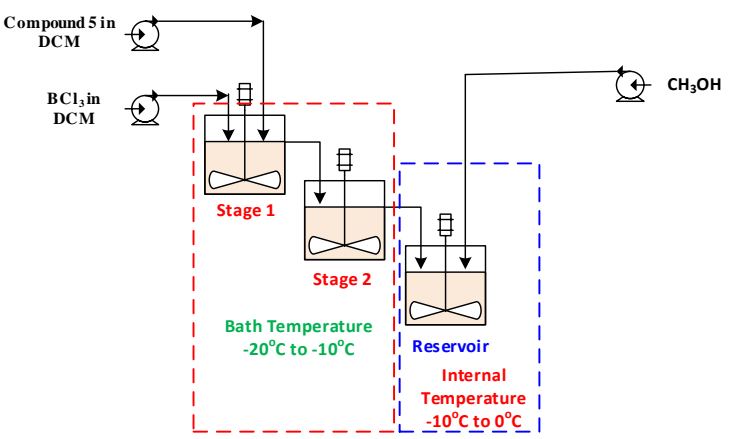

Figure 3. Schematic drawing of continuous stirred tank reactor setup.

On the basis of the above challenges associated with the batch results, a continuous stirred tank reactor (CSTR) processing mode was selected because large amounts of solids were generated during the reaction. This mode of processing offers several unique advantages to traditional batch processing, including enabling large-scale chemistry to be performed with reduced reaction volumes and improved temperature control and mixing efficiency. ${ }^{19 \sim 22}$

Based on the optimized conditions in batch mode, a continuous CSTR experiment was performed in 10V DCM (Table 5, Entry 1). During the CSTR experiment, compound 5 and $\mathrm{BCl}_{3}$ were mixed over approximately $4 \mathrm{~min}$ in CSTR \#1 and $6 \mathrm{~min}$ in CSTR \#2 to maintain the reaction at the target temperature of -20 $10{ }^{\circ} \mathrm{C}$. The result showed a large amount of Mono-Bn $(7.7 \%)$ remaining. Even when the residence time was prolonged, there was still 3.2\% of Mono-Bn remaining (Entry 2) and the insufficient mixing of the suspensions under a higher concentration was believed to be the main reason. Reducing the reaction concentration resulted in rapid reaction with high conversion (Entry 3).

A $150 \mathrm{~g}$ scale-up experiment was performed according to the optimized conditions and in-process analysis of steady flow showed $\sim 68.5 \%$ compound 6 and $0.1 \%$ compound 5 (Entry 4). However, large amounts of solids were observed sticking onto the wall of CSTRs over extended time periods leading to poor heat transfer. Increasing the volume (Entry 6, 50V) mitigated this issue. The volume of DCM has little effect on the reaction but has obvious impact on the flowability and viscosity of reaction mixture in the CSTRs. With the optimized reaction condition (Entry 6), $100 \mathrm{~g}$ scale experiments (Entries 9-10) were conducted, which proceeded smoothly to provide 6 with $63.8 \%$ yield and $98.1 \%$ purity. 
Table 5. Optimization of debenzylation continuous stirred tank reactor conditions ${ }^{\text {a }}$

\begin{tabular}{|c|c|c|c|c|c|c|c|}
\hline \multirow[b]{2}{*}{ Entry } & \multirow[b]{2}{*}{ Equiv. of $\mathrm{BCl}_{3}$} & \multicolumn{2}{|c|}{ residence time (mins) } & \multirow[b]{2}{*}{ IPC of $5(\%)$} & \multirow[b]{2}{*}{ IPC of $6(\%)^{b}$} & \multirow[b]{2}{*}{$\begin{array}{l}\text { IPC of Mono-Bn } \\
(\%)^{\mathrm{b}}\end{array}$} & \multirow[b]{2}{*}{$\begin{array}{c}\text { IPC of Di-Bn } \\
(\%)^{\mathrm{b}}\end{array}$} \\
\hline & & $\begin{array}{l}\text { reaction } \\
\text { CSTR 1 }\end{array}$ & $\begin{array}{l}\text { reaction } \\
\text { CSTR } 2\end{array}$ & & & & \\
\hline $1^{\mathrm{b}}$ & 4.0 & 4 & 6 & 0.74 & 72.4 & 7.7 & $\mathrm{ND}$ \\
\hline $2^{b}$ & 4.0 & 8 & 12 & 0.33 & 55.7 & 3.2 & ND \\
\hline $3^{c}$ & 4.0 & 6 & 8 & 0.35 & 77.2 & 2.0 & ND \\
\hline $4^{c}$ & 4.0 & 6 & 8 & 0.1 & 68.5 & 0.73 & ND \\
\hline 5 & 4.0 & 8 & 12 & 0.5 & 60.9 & 0.87 & 1.14 \\
\hline 6 & 4.0 & 4 & 6 & 0.48 & 64.8 & 0.37 & 0.26 \\
\hline 7 & 3.0 & 4 & 6 & 0.8 & 58.4 & 1.8 & 10.0 \\
\hline 8 & 4.0 & 4 & 6 & 0.29 & 69.6 & 0.53 & 0.11 \\
\hline 9 & 4.0 & 4 & 6 & 0.14 & 76.8 & 0.58 & 0.03 \\
\hline 10 & 4.0 & 4 & 6 & 0.29 & 68.0 & 0.6 & ND \\
\hline
\end{tabular}

${ }^{a}$ Reaction conditions: Compound 5 in DCM (30V) and $\mathrm{BCl}_{3}$ solution in DCM (20 V) were pumped into CSTR \#1 simultaneously.

${ }^{\mathrm{b}}$ Reaction conditions: Compound $\mathbf{5}$ in DCM $(10 \mathrm{~V})$ and $\mathrm{BCl}_{3}$ solution were pumped into CSTR \#1 simultaneously.

${ }^{\mathrm{c}}$ Reaction conditions: Compound 5 in DCM (15V) and $\mathrm{BCl}_{3}$ solution in DCM (5 V) were pumped into CSTR \#1 simultaneously.

\section{- Step 4: Reaction Screening and Impurity Profile}

The prospect of coupling 6 with 8 without protection of the 2'and 3 '-OH groups as with the current route $^{23 \sim 24}$ using cyclic acetonide was attractive as the deprotection does not proceed in high yield. Therefore, we examined the use of Lewis acids to catalyze the coupling without protection. After optimization by $\mathrm{HTS},{ }^{23} 24, \mathrm{MgI}_{2}$ was found to be the preferred Lewis Acid for coupling of $\mathbf{6}$ with phosphoramidate 8. Unfortunately, $\mathrm{MgI}_{2}$ is expensive and would add significant cost to the API. In order to mitigate this cost, $\mathrm{MgCl}_{2}$ and $\mathrm{NaI} / \mathrm{KI}$ combinations were tried to produce $\mathrm{MgI}_{2}$ in situ. The reaction comparisons with $\mathrm{MgI}_{2}$ and combination of $\mathrm{MgCl}_{2}$ and $\mathrm{NaI} / \mathrm{KI}$ are summarized in Table 6. The yield comparison between $\mathrm{MgI}_{2}$ (Entry 1), $\mathrm{MgCl}_{2}-\mathrm{NaI}$ (Entry 2), $\mathrm{MgCl}_{2}$-KI (Entry 3) indicated a $\mathrm{MgCl}_{2}-\mathrm{NaI}$ combination gave product with a better assay yield. The quantities of $\mathrm{NaI}$ in the $\mathrm{MgCl}_{2}-\mathrm{NaI}$ combination were screened with 7.0 eq. (Entry 4) and 5.0 eq. (Entry 5) and we found the condition with $3.0 \mathrm{eq} \mathrm{MgCl}_{2}$ and 6.0eq NaI gave better results. After heating overnight (Entry 5), the assay yield was similar to the reaction after 3 hours.

Table 6 Lewis acid equivalent screenings

\begin{tabular}{cccccc} 
& \\
\hline Entry & $\mathbf{6}$ & Lewis acid & Additives & Time & AY Yield a \\
\hline 1 & $0.5 \mathrm{~g}$ & 3 eq $\mathrm{MgI}_{2}$ & $\mathrm{~N} / \mathrm{A}$ & $3 \mathrm{~h}$ & $45.6 \%$ \\
2 & $0.5 \mathrm{~g}$ & 3 eq $\mathrm{MgCl}_{2}$ & 6 eq NaI & $3 \mathrm{~h}$ & $48.3 \%$ \\
3 & $0.5 \mathrm{~g}$ & 3 eq $\mathrm{MgCl}_{2}$ & 6 eq KI & $3 \mathrm{~h}$ & $7.1 \%$ \\
4 & $0.5 \mathrm{~g}$ & 3 eq $\mathrm{MgCl}_{2}$ & 7 eq NaI & $3 \mathrm{~h}$ & $12.2 \%$ \\
5 & $0.5 \mathrm{~g}$ & 3 eq $\mathrm{MgCl}_{2}$ & 5 eq NaI & $3 \mathrm{~h}$ & $32.0 \%$ \\
6 & $0.5 \mathrm{~g}$ & 3 eq $\mathrm{MgCl}_{2}$ & 6 eq NaI & overnight & $48.4 \%$ \\
\hline
\end{tabular}

a determined by HPLC assay. Reaction conditions were determined as followed: 1 eq 6, 1.2 eq $\mathbf{8}, 2.5$ eq DIPEA, 3 eq $\mathrm{MgI}_{2}$ in $20 \mathrm{~V}$ THF under 50 ${ }^{\circ} \mathrm{C}$ for $3 \mathrm{~h}$.

The reaction was further screened to check the addition order of compound $\mathbf{8}$ and the practical amount of the Lewis acids. LiI was also tried in this reaction to compare with NaI (Table 7). The milled
Lewis acids were tried and the reactions were conducted in dark to avoid potential decomposition of iodide. It was surprising to see the assay yields in these reactions were lower than those without milling, which may be due to the activation of iodide by milling and reaction in dark caused increased iodide-substituted impurity 21. This impurity shall be included in the impurity profile of this reaction.

The $\mathrm{MgCl}_{2}$-NaI combination gave better assay yield (Table 7, Entries 6 7) than the reactions with $\mathrm{MgCl}_{2}$ - $\mathrm{LiI}$ combination (Entries 4 5). The two addition methods of 8 with $\mathrm{MgCl}_{2}-\mathrm{NaI}$ combination gave similar assay yields while the reaction which added $\mathbf{8}$ at $50^{\circ} \mathrm{C}$ gave less impurity $\mathbf{2 1}$ after heating overnight. This observation led us to the optimal conditions for final scale up.

Table 7 summary of reactions to compare addition orders

\begin{tabular}{|c|c|c|c|c|c|}
\hline Entry & 6 & Lewis acid & Additives & 16 & AY Yield ${ }^{d}$ \\
\hline $1^{a}$ & 3.0 & $\mathrm{MgI}_{2}{ }^{\mathrm{e}}$ & N/A & $11.07 \%$ & $33.02 \%$ \\
\hline $2^{a}$ & 3.0 & $\mathrm{MgCl}_{2}{ }^{\mathrm{e}}$ & $\mathrm{NaI}^{\mathrm{e}}$ & $8.49 \%$ & $17.48 \%$ \\
\hline $3^{a}$ & 3.0 & $\mathrm{MgCl}_{2}{ }^{\mathrm{e}}$ & $\mathrm{LiI}^{\mathrm{e}}$ & $8.41 \%$ & $38.05 \%$ \\
\hline $4^{b}$ & 3.0 & $\mathrm{MgCl}_{2}$ & LiI & $4.24 \%$ & $34.61 \%$ \\
\hline $5^{\mathrm{c}}$ & 3.0 & $\mathrm{MgCl}_{2}$ & LiI & $3.53 \%$ & $33.34 \%$ \\
\hline $6^{c}$ & 3.0 & $\mathrm{MgCl}_{2}$ & $\mathrm{NaI}$ & $1.61 \%$ & $45.23 \%$ \\
\hline $7^{b}$ & 5.0 & $\mathrm{MgCl}_{2}$ & $\mathrm{NaI}$ & $3.05 \%$ & $46.6 \%$ \\
\hline
\end{tabular}

The impurities observed in this reaction, in addition to 21, were determined by control experiments and LC-MS analysis (Table 6). The by-products $\mathbf{2 2}$ and $\mathbf{2 3}$ observed as main peaks in the control experiments of compound $\mathbf{8}$, which were also observed in the inprocess analysis. Attempts were made to remove impurities $\mathbf{2 2}$ and $\mathbf{2 3}$ by washing with $5 \%$ sodium carbonate four times. Stress tests indicated long-time washing under basic conditions lead to hydrolysis of product 1 . After work-up, the mixture was first purified by flash chromatography and only $91 \sim 92 \%$ HPLC purity was obtained. Impurity 21 can't be separated from compound 1 by flash chromatography. Attempts to purify the crude product by crystallization were unsuccessful. Ultimately, the API was purified by Prep. HPLC to give high purity product with no single impurity above $0.15 \%$. 
Table 8 Scale-up to $100 \mathrm{~g}$

\begin{tabular}{cccccc}
\hline Entry & $\mathbf{6}$ & AY yield $^{\text {a }}$ & aq. Phase $^{\text {b }}$ & aq. Phase & Filtrate $^{\text {d }}$ \\
\hline $1^{\text {a }}$ & $10 \mathrm{~g}$ & $47.56 \%$ & $1.2 \%$ & $0.064 \%$ & $0.22 \%$ \\
$2^{\text {a }}$ & $42 \mathrm{~g}$ & $48.26 \%$ & $2.0 \%$ & $0.064 \%$ & $0.22 \%$ \\
$3^{\text {a }}$ & $51 \mathrm{~g}$ & $47.02 \%$ & $2.2 \%$ & $0.064 \%$ & $0.22 \%$ \\
$4^{\text {b }}$ & $35 \mathrm{~g}$ & $47.16 \%$ & $3.0 \%$ & $0.064 \%$ & $0.22 \%$ \\
\hline
\end{tabular}

${ }^{a}$ yield of organic phase before prep. HPLC purification; ${ }^{b}$ aqueous phase before prep. HPLC purification; ${ }^{\mathrm{c}}$ aqueous phase after prep. HPLC purification; ${ }^{\mathrm{d}}$ yield for filtrate in isopropyl ether.

With $10 \mathrm{~g}$ use test and 35 51g demo batches, $47 \% \sim 48 \%$ assay yield was obtained. After work-up, the four batches were combined together for Prep. HPLC purification. The eluent was adjusted to neutral and $108 \mathrm{~g}$ product was obtained after slurrying in isopropyl ether.

The stress tests indicated that all the operations in the work-up procedures were tolerable for product 1 except 5\% sodium carbonate washing, which indicated product 1 was stable for $3 \mathrm{hrs}$. and with $\sim 7 \%$ hydrolysis after $20 \mathrm{hrs}$. The structure of the hydrolyzed impurity $\mathbf{2 4}$ is shown in Table 6 and was established by LC-MS.

\section{Conclusions}

In conclusion, a four-step route to synthesize Remdesivir was ${ }^{1}$ developed, and the process robustness was confirmed by several demo batches in step 2 and 3 with Flow chemistry and continuous processing. Step 1 still needs more detailed information to have a fully developed process, it could be solved by other commercial vendors but some key information was missing in the published papers. Preliminary progress was achieved by using unprotected 6 in a single step with $40 \%$ isolated yield of Remdesivir. Additional studies to improve the yield of this step will lead to further cost reduction of this important therapy.

\section{ASSOCIATED CONTENT}

\section{Supporting Information}

\section{AUTHOR INFORMATION}

\section{Corresponding Author}

* Liujuan Chen

Asymchem Life Science (Tianjin) Co., Ltd.

Emai: chenliujuan@asymchem.com.cn

\section{Author Contributions}

Liujuan Chen takes responsibility of step 1 and 4 .

Guowei Zhang, Jinguang Liu and Jianye Jiao take responsibility of flow chemistry of step 2 and 3.

Xin Zhang takes responsibility of HTS of hydrogenation in step 3. Han Lin and Miao Wu take responsibility of HTS of direct coupling in step 4.

N/A

\section{Notes}

The authors declare no competing financial interests.

\section{ACKNOWLEDGMENT}

We thank the Bill and Melinda Gates Foundation for their longstanding support of our research. At BMGF, we express gratitude to Trevor Laird and John Dillon for their thoughtful commentary and suggestions.

\section{REFERENCES}

1. Warren, T. K.; Jordan, R.; Lo, M. K.; Ray, A. S.; Mackman, R. L.; Soloveva, V.; Siegel, D.; Perron, M.; Bannister, R.; Hui, H. C.; et al. Nature 2016, 531, 381-385.

2. Wang. M., Cao, R.; Zhang, L.; Yang, X.; Liu, J.; Xu, M.; Shi, Z.; Hus, Z.; Zhong, W.; Xiao, G., Cell Research., 2020, DOI: 10.1038/s41422-020-0282-02020。

3. Holshue, M. L.; DeBold, C.; Lindquist, S.; Lofy, K. H.; Wiesman, J.; Bruce, H.; Spitters, C.; Ericson, K.; Wilkerson, S.; Tural, A.; et al, $N$. Engl. J. Med., 2020, DOI: 10.1056/NEJMoa2001191

4. Grein, J.; Ohmagari, N.; Shin, D.; Diaz, G.; Asperges, E.; Castagna, A.; Feldt, T.; Green, G.; Green, M. L.; Lescure, F.-X.; et al., N. Eng. J. Med., 2020, DIO: 10.1056/NEHMoa2007016

5. Gilead Sciences Statement on the Company's Ongoing Response to the 2019 Novel Coronavirus. Gilead Sciences Inc. Press Release, January 31, 2020

6. Gilead Sciences Initiates Two Phase 3 Studies of

. Investigational Antiviral Remdesivir for the Treatment of COVID-19. Gilead Sciences Inc. Press Release, February 26, 2020.

7. Sheahan, T. P.; Sims, A. C.; Graham, R. L.; Menachery, V. D.; Gralinski, L. E.; Case, J. B.; Leist, S. R.; Pyrc, K.; Feng, J. Y.; Trantcheva, I.; et al., Sci. Transl. Med., 2017, 396, doi:10.1126/scitranslmed.aal3653.

8. Siegel, D.; Hui, H. C.; Doerffler, E.; Clarke, M. O.; Chun, K.; Zhang, L.; Neville, S.;Carra, E.; Lew, W.; Ross, B.; et al. J. Med. Chem. 2017, 60, 1648-1661.

9. Butler, T.; Cho, A.; Kim, C. U.; Saunders, O. L.; Zhang, L., Patent US2010/0021425, 2010.

10. Butler, T.; Cho, A.; Graetz, B. R.; Kim, C. U.; Metobo, S. E.; Saunders, O. L.; Waltman, A. W.; Xu, J.; US Patent 10023600B2, 2018.

11. Metobo, S. E.; Xu, J.; Saunders, O. L.; Butler, T.; Aktoudianakis, E.; Cho, A.; Kim, C. U., Tetrahedron Lett. 2012, 53, 484- 486.

12. Cho, A.; Saunders, O. L.; Butler, T.; Zhang, L.; Xu, J.; Vela, J. E.; Feng, J. Y.; Ray, A. S.; Kim, C. U.. Bioorg. Med. Chem. Lett. 2012, 22, 2705-2707.

13. Djuric, S.; Venit, J.; Magnus, P., Tetrahedron Lett. 1981, 22, 17871790.

14. Xue. F., Zhou X., Zhou R., Zhou X., Xiao. D., Zhong W., Gu. E., Guo, X., Xiang , J., Wang, K., Qin, Y., Org. Process Res. Dev., 2020, DOI: 10.1021/acs.oprd.0c00172.

15. Joseph, W. S.; David, C. L., John, P. M., Atli, T., John, J. M., Rajiah, A. D., Christoph, W. Z., Ivan. V. E., Patent US 2018/0170938 A1.

16. Vieira, T.; Stevens, A.; Chtchemelinine, A.; Gao, D.; Badalov, P.; Heumann, L., Org. Process Res. Dev. 2020, DOI: 10.1021/acs.oprd.0c00172.

17. Li., Q., Groaz, E., Rocha-Pereira, J., Neyts. J., Herdewijn P., Eur. J. Med. Chem., DOI: 10.1016/j.ejmech.2020.112198.

18. Travis K. W.; Robert J.; Michael K. L.; Adrian S. R.; Richard L. M.; Veronica S.; Dustin S.; Nature, 2016, 531, 381.

19 Hessel, V. Chem. Eng. Technol. 2009, 32, 1655.

20. Gutmann, B.; Cantillo, D.; Kappe, C. O. Angew. Chem., Int. Ed., 2015, 54,6688

21. Hartman, T. L.; McMullen, J. P.; Jensen, K. F. Angew. Chem., Int. Ed., 2011, 50, 7502 .

22. Plutschack, M. B.; Pieber, B.; Gilmore, K.; Seeberger, P. H. Chem. Rev., 2017, 117, 11796. 
23. Chun,B. Y., Clarke, M., O'neil, H., Doerffler, E., Hui, H.C., Jordan, R., Mackman, R. L.,Parrish, J.P., Ray. A., Siegel, D., Patent WO 2016/ 069626 A1.

24. Liu, Z., Klapars, A., Simmons B., Bellomo, A., Kalinin, A., Weisel, M., Hill J., Silverman, S. M., Org. Process Res. Dev., DOI:10.1021/acs.oprd.0c00487. 